\title{
La contemplation des dieux animistes dans les romans du Sud
}

Boubacar Diallo Daouda

\section{OpenEdition}

12 Journals

Édition électronique

URL : http://journals.openedition.org/etudesafricaines/134

DOI : 10.4000/etudesafricaines.134

ISSN : 1777-5353

Éditeur

Éditions de l'EHESS

\section{Édition imprimée}

Date de publication : 1 janvier 2002

Pagination : 31-50

ISBN : 978-2-7132-1420-2

ISSN : 0008-0055

\section{Référence électronique}

Boubacar Diallo Daouda, "La contemplation des dieux animistes dans les romans du Sud ", Cahiers d'études africaines [En ligne], 165 | 2002, mis en ligne le 30 mai 2005, consulté le 03 février 2021. URL: http://journals.openedition.org/etudesafricaines/134; DOI : https://doi.org/10.4000/etudesafricaines. 134 


\section{Boubacar Diallo Daouda}

\section{La contemplation des dieux animistes dans les romans du Sud}

Le pouvoir de transgression de la littérature s'est accru et amplifié sous les différents âges littéraires dans beaucoup de sphères culturelles. Il touche particulièrement les valeurs morales, temporelles et spirituelles sur lesquelles les sociétés humaines ont bâti leur prestige et leur système d'organisation. La religion reste au premier plan des repères sociaux où le roman puise ses ressources matérielles et esthétiques. Son image, mais surtout celle des hommes de Dieu, depuis Rabelais, n'a cessé de se dégrader sous la plume sévère et le regard inquisiteur des écrivains iconoclastes. En Afrique, en Amérique latine et aux Antilles - la vaste sphère artistique du Sud les religions révélées pâtissent de la tendance d'une partie des romanciers à magnifier l'animisme. Leur écriture aux visées subversives loue le polythéisme dans le but inavoué de railler et de démystifier les confessions monothéistes. Nos auteurs sèment le trouble chez les adversaires de la religion naturelle africaine. La contemplation des divinités intègre les mécanismes de l'écriture romanesque des espaces littéraires émergents. Cette hypothèse pourrait se vérifier par une analyse approfondie de La contemplation des dieux animistes dans les romans $d u$ Sud. L'expérience contemplative d'une génération de romanciers du Sud est devenue un tremplin esthétique faramineux. Cette activité contemplative présente plusieurs aspects fondés sur une vision dialectique amenant quelques créateurs à envisager les dieux dans leur grandeur puis dans leur dérision. Véritable douleur, la contemplation doit sa thérapie à l'expression libidinale appelée acte d'écriture.

\section{La contemplation, une expérience esthétique?}

La religion est le terrain de prédilection de la contemplation car les adeptes de toutes les religions du monde s'adonnent à l'adoration de leur Seigneur en essayant d'en être plus près par le biais de la prière et de la méditation. 
Chaque religion - monothéiste ou polythéiste - possède sa liturgie incantatoire dotée d'une profondeur mystique qui découle de la parole sacrée. L'expression verbale originelle a créé le lien étroit de la littérature avec la religion. La méditation religieuse est le foyer même de la contemplation. La littérature étant l'art de l'imitation et de la représentation, elle a vu se développer, à un certain niveau, une forme remarquable de prière et de méditation apparentée au rituel religieux mais qui s'en est départie pour devenir une contemplation poétique.

\section{La contemplation poétique}

Le dieu Koumbasâra de la mythologie peule, séquestré dans les murailles de la déesse maléfique de Wéli Wéli et dépouillé de sa puissance transcendantale, ne pouvait être délivré qu'après avoir contemplé un mouton magique amené par le bienfaiteur Bâ Wam-ndé. Cet adjuvant affranchit ensuite Demba Nyassorou, l'autre dieu enfermé dans une gourde métallique. La contemplation exercée par de nombreux auteurs sur la société de leur temps est un acte esthétique par essence. Rabelais, Molière, Hugo, Baudelaire en littérature française, Senghor, David Diop, Césaire et Birago Diop, dans le domaine afro-antillais, ont eu une attitude contemplative devant des objets physiques ou métaphysiques. En Grèce, Achille Tatius, Chariton, Héliodore, Longus et Xénéphon d'Éphèse contemplèrent les dieux hellénistiques dans leur fiction. La création romanesque dans la littérature grecque à l'époque impériale d'Alain Billault (1991: 231) résume ce roman ancestral à «un objet de contemplation ». La littérature hellénistique, d'inspiration païenne dominée par Les pastorales, Les éthiopiques, Les éphésiaques ou alors Daphnis et Chloé, traitait fondamentalement d'aventures dans lesquelles les divinités grecques subissaient des métamorphoses identiques à celles que vivent les dieux africains à l'époque contemporaine. La contemplation convoque un comportement spirituel et matérialiste. Elle est spirituelle lorsqu'elle vise un mouvement vers Dieu. Hugo la pratiquait sous la pression de la religiosité. La contemplation est matérielle quand elle se contente de pénétrer un objet affecté d'une essence transcendantale sans déférence de la part du contemplateur. Entre dans ce registre la reconstitution des rites africains des textes ethnographiques et anthropologiques de Delafosse, Calame, Griaule, Gilbert Durand (1992) et des autres africanistes qui, au siècle dernier, caressèrent l'espoir de promouvoir les civilisations non judéo-chrétiennes

Les auteurs africains ont prolongé ces initiatives en décrivant les rapports mystiques qui les unissent au panthéon animiste. Leurs œuvres ont une communauté d'esprit avec celles spiritualistes du $\mathrm{XIX}^{\mathrm{e}}$ siècle, telles Les contemplations où Victor Hugo, emporté dans une passionnelle quête spirituelle, découvrait la foi, la sérénité et la vérité. Contempler, c'est regarder, 
savourer, aimer ou rejeter. L'acte contemplatif impose une attitude dialectique où se crée la relation de proximité, d'adhésion, de conjonction comme de disjonction entre le sujet contemplant et l'objet contemplé. Henri Benac l'assimile à « un long examen, entraînant le ravissement, et parfois l'extase, d'un objet physique ou métaphysique dans lequel la pensée s'absorbe ». La contemplation «s'accompagne de réactions affectives de tous ordres (admiration, horreur, amour) » (Benac 1988). La sensibilité contemplative traverse la littérature romanesque du Sud, avec en toile de fond la vie des Orisha, les dieux du Vodou, la ferveur ou bien la déréliction des prêtres et des sujets africains.

La sensibilité animiste des romanciers du Sud

En introduisant une nouvelle édition de La légende des siècles, Léon Cellier de l'université de Grenoble remarquait que "l'animisme du poète nous ramène à cet univers légendaire où baigne l'inconscient collectif et où nous retrouvons aussi le monde de l'enfance ». Ceci s'avère pour la littérature africaine où la contemplation qui imite les rites animistes devient une action initiatique. L'animisme, qui est le fonds culturel de nos sociétés secrètes, a été suffisamment véhiculé en littérature orale par le conte, l'épopée, la légende et le mythe. Aujourd'hui, les romanciers l'utilisent à des fins sinon idéologiques au moins purement romanesques. Ils se sentent affranchis du respect et de la complaisance à l'endroit des croyances ancestrales. Ils ne craignent pas d'en faire un objet de dérision. Ils empruntent aux traditions ce qu'elles ont de poétique mais éreintent également leurs aspects déplaisants.

L'activité contemplative de Yambo Ouologuem (1968), d'Ahmadou Kourouma (1990), des auteurs antillais comme Patrick Chamoiseau (1992) et des Latino-Américains tels que Gabriel Garcia Marquez ou Jorge Amado (1976) est représentative de l'image pittoresque dans laquelle bien des écrivains du Sud enveloppent les dieux africains. Ils affectent une conscience, une parole et des sentiments aux choses comme aux animaux. Les protagonistes de Kä̈dara de Amadou Hampâté Bâ invoquent Gueno, le Dieu suprême. Les personnages du Double d'hier rencontre demain de Boubou Hama (1973) parcourent le monde hermétique des Attakurma ${ }^{1}$. Ceux de Mamani (1980), pétris des valeurs du peuple Azna, jurent par la foudre. Mankunku de Dongala ne reconquérit l'unité cosmique que la nuit où il revient sur les lieux de sa naissance. Dans Gros plan de Idé Oumarou, le dieu de la foudre, dans une espèce de justice immanente, venge Tahirou en tuant son tortionnaire. Les héros de Monénembo (1993) accomplissent souvent les épreuves initiatiques de l'Afrique ancienne. Sibé dispense à Cousin Samba le savoir alchimique et le mystère de la nature : «[...] Le vieux lui

1. Nains en langues nigériennes. 
enseignait le secret des plantes et des animaux, lisait à livre ouvert les écritures malignes de la nature » (Monénembo 1986 : 90).

Les croyants portent des fruits magiques ou offrent de la nourriture bénie (la cola, le lait) sous l'injonction des oracles. L'accomplissement des rites comporte une fonction narrative, il participe à la circularité du récit dans Les écailles du ciel en ramenant Samba sur le lieu du début des événements. Les sorciers de Diéké et de Dori récupèrent puis enseignent à Gilles, un jeune socialiste français dégoûté de l'Occident au lendemain d'une élection présidentielle perdue par son parti. Sa formation sacrée se passa dans un climat animiste : «On me fît vêtir du boubou noir. Je tuai le castor d'un coup de sagaie » (id. 1991: 206). La scène décrite plus haut confirme les mots de A.H. Bâ et du Révérend E. Elugo (1965 : 43) : «La religion animiste relève davantage du culte et des cérémonies. » La peinture de l'animisme, c'est l'innocence momentanément reconquise. Les relations des auteurs africains et ceux de la diaspora noire avec les traditions religieuses sont d'ordre psychique et affectif. Ils s'y attachent et prêtent en conséquence leurs sentiments à des êtres de fiction. Le contact émotionnel de Boris Diop ou de Raphaël Confiant (1997) avec le monde ancien coïncide avec les rapports entre Senghor et les esprits animistes. Le Sénégalais charge sa poésie de références panthéistes. La relation sentimentale qui le lie à la nature divinisée justifie sa dévotion et sa déférence pour les masques.

Le poème Prière aux masques célèbre les dieux d'Afrique et débouche sur une quête spirituelle où le poète tire un double effet mystique et musical qui sourd des sonorités sifflantes et liquides : «s », «f», «1»: «Masques aux quatre points où Souffle l'esprit, Je vous salue dans le silence. » Le dieu Gongoloma-Sooké, «L'ombre », le sésame, le figa prouvent l'intérêt littéraire de l'objet rituel. La redondance des chiffres cabalistiques et des adjectifs de couleur dans la caractérisation des mascottes concède une atmosphère païenne aux textes romanesques du Sud. Les divinités animistes contribuent au drame des œuvres au même titre que leurs sœurs de la littérature grecque. Elles ont une fonction poétique et symbolique à cause de la spiritualité et des descriptions qu'elles suscitent. Pour Benac, «non seulement une description peut contenir une atmosphère qui renferme le drame mais elle fait sentir une sorte de vie qu'ont les choses en elles-mêmes ». En Afrique traditionnelle, confiait Amadou Hampâté Bâ (1994 : 43), «on ne s'adresse jamais à son supérieur que par un intermédiaire immédiatement au-dessus de vous, d'où l'intercession des ancêtres ou des divinités inférieures $»$.

L'intermédiation est une coutume divine. Dieu ne s'adresse pas directement au peuple. Il élit un messager au sein de la gent humaine. Gueno remit le bâton magique du berger à Kîkâla chargé de le transmettre à Bouytôring dans Les contes initiatiques de A. H. Bâ. La description des divinités irrigue le dispositif narratif des textes. Dans Un attiéké pour Elgass, l'évocation du sassa produit des passages saisissants par leur ésotérisme et lyrisme (Monénembo 1993 : 75) : «Ce n'est pas un sassa comme les autres. [...] Il 
est teint d'une double couche de pochettes, sept en tout [...]. La base est gravée d'une étoile à sept branches. L'étoile, c'est la lumière qui éclaire le chemin du berger. Le nombre sept est la clé qui ouvre les portes du bonheur [...]. »

La description du sassa a exigé l'emploi redondant de l'auxiliaire être. La copule restitue la qualité immuable des choses. Ses multiples occurrences créent un effet sonore. Les anaphores du nombre «sept » secrètent leur part de mélodie. Elles affectent au fétiche une valeur émotive, l'habillent d'un caractère ésotérique et le campent dans une origine mythologique où foisonnent des sens spirituels. La présentation affective du sassa s'effectue par le biais du procédé de l'hypotypose définie comme une peinture des «choses d'une manière si vive et énergique qu'elle les met sous les yeux » pour en faire « un tableau » ou même « une scène vivante » (Dupriez 1984: 240). L'hypotypose expose les images visuelles et idéelles du gri-gri familial emporté par Elgass en fuyant la Guinée après l'indépendance nationale qu'il soupçonnait de perversion. La mise en relief du porte-bonheur sollicite nos yeux et notre imagination. Le lecteur ne verra pas l'objet précieux, il ne savoure que sa photographie grâce à une tirade descriptive concrétisant la stylisation aspectuelle, organique et fonctionnelle de l'amulette. L'énigmatique gri-gri, réel et imaginaire, se mue en chose mystérieuse et poétique telle le Graal de la mythologie scandinave (La Queste del Saint Graal) que Galaad compare aux «merveilles de toutes les merveilles » (Sansonetti 1987 : 83). La quête du sassa menée par Idjatou bascule dans une opération rituelle et contemplative (id. : 75) «On m'a éduquée dans le culte de ce bien de famille. Mon père disait que le sassa renfermait la tradition de notre destin... » Le fétiche est revêtu des apparences d'un puissant symbole, celui de la pérennité d'une culture archaïque malgré les influences étrangères et les tribulations y afférentes : «Je sais maintenant qu'il ne s'agissait pas de n'importe quelle babiole, mais du totem de toute une lignée. » Le langage métaphorique remue l'âge et les souvenirs olfactifs de l'objet philosophal, indicible, fabuleux, éclectique et auguste qui s'origine dans le réceptacle « œcuménique » médiéval : «[...] On aurait pu le repérer à son odeur de Tassili, sa couleur du Ghana, son âge sans nombre des Malis, l'éternité de ses plis songhaïs et foutas. »

Les romans du Sud déroulent un univers hermétique. Les personnages implorent les dieux dans des termes empruntés à la liturgie de l'Égypte pharaonique où Horus déclame des poèmes et dit des prières à la gloire de Isis et Osiris. L'animisme entre en résonance avec les rites d'Artémission de la Grèce antique. L'évocation du figa (Pelourinho) ravive ce genre d'opérations. La quête de l'identité qui préoccupe la majorité des personnages tourne à l'obsession chez le héros posthume du livre. Sous un mode parodique du complexe œdipien, le texte personnifie longuement le figa qui désigne les scarifications qu'un roi africain déchu au $X I^{\mathrm{e}}$ siècle a répandues au Brésil. La séparation entre l'Afrique et l'Amérique s'éprouve comme un 
tort à redresser. La mer reste, dans la sensation de cette douloureuse injustice, une adversaire à dompter. Africano, l'ancêtre symbolique d'Innocencio, le premier narrateur (il s'agit d'un double récit d'inspiration faulknérienne, conduit par un fils qui ignore sa mère, l'autre narratrice), ambitionne de la neutraliser : « Je veux rabibocher le présent et l'autrefois, amadouer la mer » (Monénembo 1995 : 150). Les mystérieux tatouages claniques représentent un secret à percer : "Tu vois, je commençais à faire miennes tes obsessions généalogiques. Les figas, les chaînes, les dieux rois et les hymnes se sont mis à m'encombrer l'esprit » (ibid. : 116). Innocencio méprise les obstacles, entame sa quête avec « un procédé de flic : discrétion fébrile, prudence et tact » (ibid. : 148). Malgré les gifles du commissaire Bidica, il scrute goulûment le remarquable figa de Tigrado (l'un des redoutables frères Baeta) déshabillé par la police à la plage. Les frères Baeta puisent leur rage et leur témérité dans la force vitale des signes ancestraux. Les opérations rituelles sont récurrentes dans les romans de Tierno Monénembo. Le plus récent, L'aîné des orphelins, consacré au génocide rwandais, y revient à travers le sorcier Fuga qui assurait l'intermédiation entre les hommes de Nyamata et les dieux tutélaires. Les objets rituels des romans africains méritent paradoxalement les vénérations ou les longues quêtes-solitude du héros sanctionné par la révélation parsemée d'embûches. Les auteurs soulignent par là leur sensibilité animiste. Mais, ils ne se contentent pas de la peinture idyllique et apologétique des rites ni de la contamination du panégyrique. Ils se détachent de ces occupations ancestrales pour les contempler sous l'angle de la dérision et dessiller les yeux du lecteur sur le destin des forces animistes.

\section{Grandeur et dérision des dieux animistes}

La grandeur des dieux africains a amorcé leur déclin avec la détérioration de leurs conditions de vie. Ils subissent les crises liées aux vicissitudes de l'Histoire. Les auteurs de notre corpus qui ont le goût de la démesure regardent cette situation avec une désinvolture à la limite de la subversion.

\section{Le tempérament subversif des romanciers du sud}

Les romanciers stylisent les dieux africains dans un ton satirique et ironique. Les divinités décadentes oscillent entre grandeur et dérision. La description narrativisée des rites mêle la parole incantatoire au langage ordurier de la vie profane. Ouologuem invite ses camarades de combat à ce jeu irrévérencieux et subversif envers la religion naturelle africaine. Il a situé sans le moindre égard pour les cultes, des agissements luxurieux sur les lieux de divination quand une servante vint solliciter la bénédiction de son enfant auprès du mage du village. 
L'invocation prit une tournure lascive : «Les yeux du sorcier lancèrent des éclairs et malgré elle, la servante se sentit hypnotisée. L'homme la voulait. Elle le détestait » (Ouologuem 1968 : 148-149). Le village de Kolisoko saccage impunément la case du sorcier Sibé, contrairement à Sarsan de Birago Diop (1947: 180) que les puissances transcendantales rendirent fou après son sacrilège. Il psalmodiait le reste de sa vie l'omniprésence des morts : «Les morts ne sont pas morts. Ils sont dans le bois qui gémit, dans l'eau qui coule. »

Les romanciers procèdent de plusieurs façons pour dévaloriser les objets rituels sanctifiés au début des textes. Le temps déprécie les noix de cola de Cousin Samba en les pourrissant. Il épuise leur pouvoir protecteur : "Quand Cousin Samba sortit ses sept noix de cola de sa poche et que par un geste incantatoire, il les fendit, il découvrit avec moi qu'elles étaient toutes avariée » (Monénembo 1986: 192). Les personnages arrachent aux choses vénérées leur caractère sacré. Certaines matières végétales ou biologiques ont dans le fétichisme une fonction de régénération ou de dégénérescence des dieux. Le lait et le sang frais revitalisent les divinités là où l'urine les désacralise. Les sanctuaires périssent dans Un rêve utile où la milice et les soldats de Boubou blanc les enjambent sans rien risquer : «Il fallait au plus vite faire cesser les rites ancestraux, les usages barbares qui déshonoraient la race. Les miliciens et les soldats assaillirent les forêts et les brousses pour arrêter les mages, les prêtres et les enchanteurs » (id. 1991 : 240-241).

Les hauts lieux souillés et incendiés, tombent dans la banalité. Amadou Hampâté Bâ (1994 : 143) accusait le temps d'être le seul «ennemi qui entamera [notre religion], comme il a entamé au cours des âges bien des institutions qui paraissaient pouvoir défier l'éternité ». L'espace sacré se disloque au fur et à mesure que les événements s'accumulent et s'accélèrent. Il déchoit avec une facilité démoralisante malgré sa puissance claironnée. Nazi Boni a déjà averti les siens : «Une nouvelle puissance arrive qui oblige [nos dieux] à se terrer »(Boni 1962: 217). Certains Africains et parfois quelques-uns de la diaspora caricaturent la culture animiste en plaçant des actions grossières sur les autels. Ils élaborent une image contrastée des dieux et observent une distanciation ironique à l'endroit des événements qui se rapportent aux traditions. Ils suggèrent la complainte, la désolation et l'agonie des temples. L'âge animiste s'éclipse pour céder la place à une autre ère où le domaine sacré s'ouvre à l'espace profane qui l'annexe et la phagocyte. Ce mélange des registres marque plusieurs romans du sud. Jorge Amado l'a pratiqué avec Les chemins de la faim, Bahia de tous les Saints et La boutique aux miracles où les valeurs d'hier obscurcies subirent des transformations atroces sous l'action néfaste de la modernité. Le rire de l'auteur en atténue le tragique mais aussi la vénération en conformité avec la conception que se fait Mikhaïl Bakhtine dans Esthétique et théorie du roman de l'ironie en tant que faculté humaine. La ressemblance est forte entre Jubiaba ${ }^{2}$ (un prêtre séquestré avec ses danseurs de Macumba par la

2. Jubiaba est le prêtre africain dans Bahia de tous les Saints de J. Amdo. 
police brésilienne) et le Doyen Tchiombiano que la milice guinéenne jeta en prison. Les romans africains, antillais et latino-américains de cette trame ont un relent d'héroïsme baroque, d'épopée paradoxale et moderne à l'image de ce sage africain qui magnifie la magie : «Ah! non l'eau douce est plus forte que le feu qui crépite; l'œil qui n'a pas de voix, dit mieux que la bouche qui hurle» (Monénembo 1991 : 236-237).

Face à certains grands bouleversements comme le génocide rwandais, les sorciers eux-mêmes sont gagnés par le doute. Ainsi, Funga (L'aîné des orphelins) a décidé au lendemain du carnage dans son village de se débarrasser de ses grimoires, conscient qu'il était qu'une telle tragédie ne pouvait pas se produire si Dieu existait.

Notons le sarcasme d'Ahmadou Kourouma qui feint la surprise de voir les Blancs traverser la colline Kouroufi «truffée de sortilèges » (Kourouma 1990 : 34). Il tourne en dérision les sacrifices propitiatoires excessifs consentis par les Malinkés pour conjurer le sort en les assimilant à un acte de Sysiphe. Ces rites faits aux dieux tutélaires n'empêchent pas les Européens de souiller les autels et de soumettre le village.

L'esprit animiste se fonde sur la morale de la crainte. Or, aujourd'hui, à cause de l'évolution des mentalités et des idées, ce sentiment n'existe plus chez bien des hommes. Les textes de notre corpus constatent la douleur des dieux animistes dans un monde de souffrance et de déréliction. Ils ébranlent des certitudes: les dieux endurent les mêmes peines que leurs adorateurs dont ils seraient de surcroît des semblables: "Les divinités sont à l'image des hommes. Elles ont leurs géants, leurs bossus, leurs valets, leurs gueuses, leurs pandores, leurs fous, leurs bouffons et bien entendu leurs rois [...] toutes les formes de nos semblables » (ibid. : 218). Dans un rêve utile, la redondance moqueuse de «dieux », ridiculise les puissances supérieures où le récit mise sur la déconfiture des valeurs antiques par le biais d'une cadence prosodique saccadée calquée sur le rythme et la mélodie du « Dondooru » ou fantastique en fulfulde (Monénembo 1991 : 77, 182, 200) : «Les dieux, ils créent, ils oublient d'allaiter, Les dieux, ils nomment, ils oublient de rétribuer, Les dieux, ils donnent la vie, mais c'est à chacun de la gagner. » L'oubli réfère à la limite de la mémoire humaine. Suggérer qu'il touche les dieux, rabaisse ceux-ci à la mesure de l'homme et les inscrit dans la détermination naturelle d'une déchéance annoncée remuant le destin tragique du Noir, la chute de l'humanité avec ses flots d'images funestes.

\section{La descente aux enfers des dieux africains}

L'œuvre des divinités africaines ressemble à un travail inachevé. Chateaubriand a laissé un précieux éclairage sur la puissance relative des dieux des religions polythéistes. Se référant au panthéon grec, il soutint que «ces dieux ne sont qu'une espèce d'hommes supérieurs que l'on est libre de faire agir comme les autres hommes »(de Chateaubriand 1966 : 322-323). Les 
dieux ou les ancêtres «canailles » et burlesques ont véritablement existé dans la mythologie africaine tels qu'ils apparaissent dans L'Unité culturelle de l'Afrique noire de Cheikh Anta Diop (1959 : 219). Une partie des romans du Sud brasse cette image triviale « des barbes blanches », une synecdoque humoristique visant les patriarches. «Les sages [...] deviennent galopins sitôt franchie la ligne bleue des nuits éternelles... » dans Un rêve utile. La vérité des sages, relative et contestable, s'amenuise. Les romanciers interprètent ce rabaissement de l'Olympe africain par la nature même des esprits animistes : «Il y a une espèce de grandeur et de dérision dans la vie des dieux païens africains. Vous avez des dieux mais d'une force et d'une beauté totales et vous avez des dieux bornés, des dieux qui pleurent. Et chez les Grecs, c'est la même chose » (Daouda 1997: annexe 1: 8).

Sans être très attachés aux croyances ancestrales, les personnages africains, antillais et latino-américains feignent de les perpétuer et d'y rester fidèles. Arrachés du milieu animiste, ils n'en sont pas moins rattachés par l'emploi d'un langage superstitieux. Ils invoquent Chango, Olorun du panthéon yoruba, les prêtresses du Vodou haïtien. Derrière l'apparente confiance dans les dieux, se réalise une intention sarcastique et démystificatrice. Les romanciers exposent ce côté ostentatoire de l'animisme. Ils s'en gaussent d'une part et s'en servent comme matériau stylistique de l'autre. Ils injectent la force expressive de la parole incantatoire dans les mécanismes de l'écriture sans en éliminer les excès.

Le détour de Galant-Métro chez le thaumaturge de Loug sert de prétexte pour glisser l'expressivité de l'impératif dans Un rêve utile. L'exubérance langagière des magiciens surgit au travers du parler des deux personnages inspiré du sacerdoce animiste. Galant-Métro se faufile dans la foule, grigri au cou ou noix de cola dans la main, avec l'espoir d'influer sur la décision d'un administrateur français xénophobe, d'autoriser sa femme à le rejoindre en France : «Entre temps, il a manqué de renverser une passante parce que le talisman qu'il s'est mis au cou ne tolère pas qu'on dévie de son chemin » (Monénembo 1991: 124).

Le narrateur doute de l'efficacité de la magie dans une société profane comme celle de Loug. Il confronte le rationalisme occidental et le fidéisme africain : «Le plus périlleux, évidemment, sera de laisser tomber la noix de cola blanche sans que chaque fois il y ait un malappris pour lui rappeler qu'il a perdu quelque chose. Le Wali, ce n'est pas de sa faute si ses oblations vont mal avec la mythologie d'ici » (ibid. : 125). La force de transgression de la littérature permet de prendre de haut les adeptes de l'animisme qui ne sont plus l'incarnation des dieux dans le monde ici-bas. Seules les dimensions solennelle et poétique, mi-barbare et mi-mystérieuse des rites intéressent les créateurs. Ils exposent la dérision des dieux au sens de la «Dérision du Christ » inspirée des visions iconographiques de Anne Brigitte de Suède ; dans un monde qui les malmène et torpille leur essence. Le figa (Pelourinho) se métamorphose finalement en un banal bijou dont se pare tout Bahia. Les pratiques animistes qui le perpétuent dégénèrent en cérémonie 
carnavalesque. L'Amérique latine et l'Afrique fusionnent, l'une s'efforçant par la poussée du sentiment filial, d'être le prolongement naturel de l'autre : « Nous sommes tous ici sous la protection d'un figa ( ibid. : 137). Engagée au début du récit, la quête s'achève dans le sang. Les figas survivent chez des délinquants qui terrorisent la favela de Salvador. Le narrateur les retrouve et organise une rencontre avec «leur cousin vieux d'un siècle ». L'humour bouscule le sérieux. Le quiproquo et le hasard accouchent de la dérision et de la violence.

Les frères Baeta assassinent par méprise Escritore sur un tas d'immondices. Daniel Delas (1996 : 109-110) a comparé ces événements à « un carnaval des identités ». Le destin du figa éclaire le lecteur sur des individus sans scrupules et dont la vie quotidienne se ramène à de tragiques histoires d'argent, de drogue, de sexe et de sang. Ils ne s'attachent à aucune valeur, pas même au figa authentique dont ils ont hérité. En Amérique, en Afrique, aux Antilles, les dieux sont associés à une existence de rapines et de crimes. C'est l'image pittoresque et tropicale que quelques écrivains leur ont trouvée. Ceux-ci dressent le bilan du monde ancien dont les valeurs n'apportent aucune réponse satisfaisante aux crises modernes.

La qualité de leurs textes, où agissent des déracinés, des dieux troublés et orphelins, se trouve dans la montée permanente des désirs difficiles à combler. Tigrado en porte quelques stigmates : "Mon père serait reparti pour voir un peu le relief des origines. Peut-être le ferai-je à sa place ?» (ibid. : n. 7 : 180-181). Il faut entendre ici la vanité du retour aux sources, ce n'est guère une préoccupation sérieuse pour le bandit de Salvador. Les épanchements et les envolées lyriques jaillissent de la poétisation des objets rituels mais que la majorité des textes démolissent. Les personnages, tous antihéros, dérivent en ville sans repères, sans sécurité, traversent les milieux mondains, mènent une vie libertine. Les quêtes qu'ils initient suscitent la méfiance et manquent de crédibilité. Innocencio alerte le lecteur sur ce paradoxe : «Quand on boit autant, on ne doit pas perdre son temps à raccommoder l'histoire » (ibid. : 27). Rapprocher l'Afrique et l'Amérique latine devient problématique. La revitalisation des divinités afro-américaines reste à réaliser. Les bases ont été jetées par le canal de la poésie. Les romans africains de cette veine réveillent le souvenir d'une œuvre très sud-américaine, Le partage des eaux d'Aléjo Carpentier où le héros entame une longue quête sur la minorité indienne de la forêt amazonienne. La remontée des eaux d'un fleuve légendaire sert d'alibi à une peinture idyllique et un rappel incessant de la grandeur de la civilisation primitive soumise malheureusement aux périls inhérents au modernisme.

Mais à la différence de Carpentier chez qui la mort du passé crée une nostalgie mélancolique, les auteurs africains procèdent à leur autodérision. Ils attaquent leur mal autrement. Ils ne répugnent pas à parodier les sujets les plus sérieux, les plus exaltants. Le retour aux sources, la quête des racines, le mysticisme dénotent la dérision et la folie du monde. La fin des romans 
opère souvent un retour retentissant à la culture populaire faite de superstitions, de croyances, de pacte sacré et de trahison. Tout Salvador déifie par exemple Africano. La favela suppose qu'il désertera sa tombe et rejoindra l'Afrique, terre délicieuse des ancêtres. Ce sera la traversée héroïque des eaux hostiles (la mer) pour immerger dans les eaux originelles et purificatrices. Une certaine vengeance (utopique ?) sur l'Histoire cruelle (ibid. : 217) : «Pas plus de trois jours dans le trou où on l'a mis [...] il se transformera en balbuzard. Il lui suffira alors d'un coup d'aile pour traverser la mer. » L'accent faulknérien et kafkaïen des textes, c'est-à-dire l'absurdité, la dérision des faits, conforte la relativité de la grandeur des dieux. Les romanciers les divinisent puis effacent leur essence sacrée. Ils atténuent l'amertume éprouvée au sujet de la traite des Noirs et de tous les supplices qu'ont endurés les peuples colonisés. Ils effectuent une descente parodique dans la mythologie africaine comme James Joyce (1992) l'a tenté avec Ulysse et Thomas Mann (1965) dans Les Buddenbrook, à propos de la civilisation occidentale.

L'art a ainsi une puissante fonction cathartique que l'on pourrait puiser au Sud dans les limbes de l'imaginaire. La satire sociale et politique informe notre roman. La contemplation des dieux animistes se déroule dans une vision sentimentale et humoristique. Les auteurs africains regrettent la déliquescence du passé. Ils expriment leur nostalgie d'hier par un rire inquiétant et sceptique.

Comme toute forme de contemplation esthétique, la leur charrie des sentiments contradictoires. Les dieux qu'ils aiment et adorent, ils les flagellent pour mieux supporter la douleur que leur affaiblissement provoque en eux. Ils partagent ce drame psychologique avec les Latino-Américains: Jorge Amado, pionnier dans cette thématique, ou Gabriel Garcia Marquez qui donna à son tour une profondeur dramatique et métaphysique au déclin des valeurs anciennes. L'extrême richesse du destin baroque des dieux a attiré certains auteurs africains. Elle les a contraints à fouiller dans le foisonnement du roman brésilien, cubain ou colombien. On peut saluer l'enthousiasme avec lequel ils exaltent l'animisme et le tournent parallèlement en dérision. Une sagesse enseigne que la relation sentimentale s'accommode toujours de l'attitude ambivalente au sens psychanalytique et freudien du mot. Les romanciers africains et ceux de la diaspora noire surprennent dans la double destinée des dieux un remède au sentiment douloureux qui les envahit devant l'absence émotionnelle du passé.

\section{L'acte d'écriture comme thérapie de la douleur de la contemplation}

L'écriture, forte de sa vocation cathartique, guérit la douleur occasionnée par la contemplation. Les auteurs de notre corpus se livrent d'abord à une vive contestation des religions révélées avant de laisser libre cours à leurs penchants anarchistes. 


\section{La contestation des religions révélées}

La contemplation bouddhiste (le nirvâna) est caractérisée par l'absence de douleur et la possession de la vérité dans sa dernière phase. Les autres formes de contemplation se cristallisent elles aussi sur l'accès à la connaissance et à la vérité, mais sont pénibles à toutes les étapes. L'activité contemplative est narcissique car elle répète la souffrance d'Ovide dans Les métamorphoses. La contemplation, même esthétique, est un complexe ovidien, un narcissisme douloureux. Les Africains et les Américains du Sud qui traduisent leur déception devant la ruine du passé découvrent qu'ils n'y peuvent plus rien. Les valeurs dont ils se réclament «[...] ont vu leur panthéon bouleversé et leurs rituels transformés » clame J.-P. Olivier de Sardan (1995 : 69). Le miroir ancestral où les romanciers se mirent est brisé en petits éclats difficiles à colmater. Cette certitude les pousse à envisager des solutions compensatoires. Ils entretiennent des rapports conflictuels avec les religions révélées, responsables de la disparition de certaines pratiques animistes. Cette hostilité est sensible dans l'attitude iconoclaste, la volonté de subversion et le désir de déchirer les agresseurs des prêtres noirs.

Les textes africains de cette sensibilité fonctionnent comme les œuvres de Jorge Amado, qui, en contestant vigoureusement la religion d'État, a contribué à l'intérieur du roman d'Amérique latine, au surgissement de relations antagoniques entre les adorateurs des oracles et le pouvoir politique. Comme il le fit avec les figures messianiques de Zéfa et de Jubiaba, Boris Diop (1987) affecte un caractère divin respectivement à la reine Johanna Simentho et à la Sainte du Nord. Le patriarche Boureima des Tambours de la mémoire, admirateur de la déesse Johanna Simentho, est frappé de cécité le jour où les Blancs assujettirent son royaume. Le vieillard se garda de croiser le regard des tristes représentants du Christ. Le roman de Boubacar Boris Diop élève la reine Johanna Simentho en une figure emblématique de la lutte que les forces religieuses locales mènent contre les étrangers. Il l'a brodée avec des traits christiques pour des raisons blasphématoires. Le peuple attend le retour de la reine. Le schème religieux de l'attente du Juste est fortement remué ici. La libération de l'Afrique serait effective avec la résurrection de la divinité idolâtrée par les Noirs. La déesse de la pluie, du bonheur, de la résistance et de la paix, symbole de totalité, est dotée de puissance magique. Elle se rend visible ou invisible au gré de sa volonté. Les pages 190 et 191 exposent la mission civilisatrice assignée à ce messie. Johanna Simentho serait l'envoyée de Baliba, le Dieu suprême de Wissombo. Fadel, le héros du texte, a entrepris une longue quête initiatique après des rumeurs persistantes sur sa mort. À la suite de bien d'autres auteurs africains, Boubacar Boris Diop utilise la fiction, l'imaginaire pour élaborer des croyances nouvelles destinées à remplacer les défuntes. Cependant, à la lumière du destin de Fadel, la contemplation ou communication avec les génies et les dieux (Bounfour 1994) s'opère dans la douleur. D'ailleurs, battre les tambours de la mémoire, n'est-ce pas refuser l'oubli et 
contester l'ordre établi ? Et comme le prouve le récit, pareille passion est mortelle. Fadel accéda à la connaissance, à l'amour et à la vérité. Puis il mourut violemment, car les forces qu'il combattait étaient farouches, plus puissantes et impitoyables. Son père supportait ses opposants. Le mélange du drame familial et de la fresque sociopolitique préfigure l'épaisseur psychologique et la beauté des Tambours de la mémoire.

La Sainte du Nord arbore le même visage dans Le feu des origines de Dongala. Les Africains en ont fait leur Sainte Marie. Elle procréa sans avoir connu d'homme puis prêchait un nouvel évangile qui dévalorisait les gnoses chrétiennes. Les forgerons récupéraient les croix du Christ, les fondaient et en fabriquaient d'autres au nom de leur prophétesse. Quel esprit subversif! La reine du Congo vécut sa part de détresse. Elle fut humiliée par les forces allogènes acquises à la cause du christianisme et de la colonisation. Le peuple partagea sa douleur dans un long recueillement. Les romanciers du Sud auxquels cet article s'intéresse sont à la recherche d'une stabilité morale et sociale. Ils traversent dans la complexité de la relation coloniale les «fluctuations de l'identité culturelle» circonscrites par Albert Memmi ${ }^{3}$. Ils s'indignent des perturbations de leurs normes de référence. Les valeurs ancestrales ont permis autrefois de vivre dans la stabilité, l'assurance et la quiétude. Le drame de l'Africain d'aujourd'hui et de la diaspora noire, c'est que la tradition n'a pas de réponse à toutes leurs inquiétudes. La nécessité de l'autoréalisation pousse les romanciers à dépasser les motivations de la déchéance des dieux pour inventer ce qui peut se substituer à eux, c'està-dire participer à l'émergence d'autres mythes fédérateurs après avoir célébré par le verbe les funérailles du vieux monde.

La petite phrase de Hugo dans Magnitudo Parvi a valeur de maxime: «Contempler les choses, c'est finir par ne plus les voir. » La contemplation est un regard de l'intérieur et de l'extérieur; un acte d'écriture sublimant la sensation de la perte de l'identité à travers lequel les auteurs consentent à mettre à mort les éléments référentiels du passé. La création artistique console les auteurs, elle conserve les valeurs ancestrales qu'ils revendiquent très fortement, elle permet enfin la distanciation lucide. Elle interroge ici le passé et le présent par une exploration poussée de l'imaginaire et le déploiement de l'esthétique et de l'éthique de la dérision sous la coupe d'un anarchisme foncier.

La tentation anarchiste des romanciers africains, antillais et latino-américains

C'est dans des romans tels que Comment faire l'amour avec un nègre sans se fatiguer de Dany Laferrière et Les écailles du ciel de Tierno Monénembo qu'apparaissent mieux, sous différentes formes stylistiques, l'anarchisme qui

3. Une expression due à A. Memmi. 
féconde le roman du Sud. Le bouleversement des sociétés secrètes est ironiquement présenté dès la seconde œuvre de Monénembo (1986: 33) en tant que menaces prémonitoires : «[...] Le monde serait à l'envers : [...] l'enfant accoucherait de sa mère, la terre serait là-haut et le pauvre ciel piquerait du nez vers les profondeurs du bas. » Conscients de l'irréfutabilité du chaos, les personnages se résolvent chaque soir à boire «au désordre du monde jusqu'aux confins de l'aube» (id.: 153). Avec les textes suivants, le pire arrive aux traditions locales. L'auteur en profite pour rire tendrement de l'animisme, déverser sa colère sur l'ordre politique nouveau qui traumatise les citoyens en les empêchant d'exercer leur liberté confessionnelle. Monénembo persifle les sages à travers des scènes bouleversantes où les femmes et les enfants travestissent le pouvoir de commandement. Cet événement exceptionnel survient la nuit ; un instant où le temps païen évacue le conformisme et l'ordre naturel: "Ce sont les femmes qui portent le baraya, qui commandent aux hommes et aux dieux. Ce sont les enfants qui s'attichent de barbiches en feuilles de maïs et qui pourchassent, fouet à la main, les sacripants aux cheveux blancs » (ibid. : 29).

Le romancier brosse le topique carnavalesque de la destitution du roi. Au carnaval antillais et brésilien, après avoir paré le roi, fêté à ses côtés, les réjouissances se terminent dans une ambiance baroque où la foule met le feu à sa majesté. Les intrigues nocturnes d'Un attiéké pour Elgass mettent en veilleuse les normes étatiques au profit des forces animistes. Au coucher du soleil, une femme fantomatique, voisine de la Médée d'Euripide, s'accapare les pouvoirs de décision et d'action. Tantie Akisi, la doyenne du roman en ébauche ce portrait effrayant, tissant l'image effroyable des trois Gorgonnes $^{4}$ de la mythologie grecque (Monénembo $1993: 43$ ) : «Je la connais, cette femme. Elle vit loin du monde [...]. Elle a des plumes au ventre, des serpents pour collier. Son cœur a la taille d'une tête d'épingle.»

La déesse maléfique et pyromane, une sorte de Njeddo Dewal urbaine ${ }^{5}$, manigance des accidents de la circulation, des incendies mystérieux et la déchéance des hommes de Dieu. Elle les implique dans des actions déshonorantes : fornication, consommation d'alcool, goût du mensonge ajouté à celui de la félonie. Les religions révélées souffrent de l'ironie gogolienne ${ }^{6}$ des romanciers qui décrient l'hypocrisie des prêtres et des marabouts. Leur démarche profite à l'animisme. La tradition perd du terrain, mais à leur tour, les rites sensés la remplacer entament leur pourrissement du fait de la corruption de ceux qui les pratiquent. Le roman africain ravive les soirées païennes et décrit l'ivresse collective de nature bacchanale (Bessis 1987)

4. Un tableau de Gustav Klimt (1862-1918) repris par C. CARLIER \& N. GRitToN ROTTERDAM (1994: 85).

5. Njeddo Dewal (la septième femme en fulfuldé) est la mère de la calamité dans un mythe peul du même titre rapporté par Amadou H. Bâ.

6. Nicolas Gogol a contemplé les traditions russes menacées par la modernité dans une veine subversive comparable à celle de certains romanciers du Sud (Le manteau ou Les soirées du hameau). 
où se condensent les plaisirs dionysiaques : orgie, musique, danse, extase, transe, sorcellerie et sexualité. Les dieux métamorphosés par la force des choses, vivent leur altérité. La désorganisation générale reflète un fantasme populaire : le désir inconscient des Africains de déstructurer les pouvoirs aristocratiques et théocratiques qui les maintiennent dans une étouffante négation des libertés. Les auteurs se plaisent à exagérer la dénaturation du monde traditionnel. Ils foulent aux pieds les fonctions sociales et politiques qui régissent les vieilles et nouvelles sociétés humaines. La transgression puis l'inversion de l'ordre normal du monde traduisent la tentation anarchiste qui bouillonne en eux. Ils décrivent «un pays halluciné » où « la jugeote ne [se trouve] qu'au bagne », «l'idéal au cimetière » et «l'eau partout sauf aux robinets » (Monénembo 1993).

Ce penchant anticonformiste structure pour une large part la matrice des œuvres romanesques du Sud. Il transparaît dans Les méduses et les orties de mer de Tchicaya U'Tamsi, La vie et demie de Sonny Labou Tansi, Le jeune homme de sable de William Sassine, Une peine à vivre de Rachid Mémouni, Les derniers rois mages, Célanire cou-coupé de Maryse Condé ou Allah n'est pas obligé de Ahmadou Kourouma. Les écrivains perçoivent l'irréversibilité de la décadence du vieux monde, ils grossissent et accompagnent les causes qui la provoquent. L'anarchisme se voit par exemple dans la valeur positive que prend la nuit, le temps animiste par excellence, au détriment du jour plutôt propice à l'expression des normes sociales et au règne du conformisme : "Puis l'aube est venue ranger les calebasses de dolo et les tambours de la réjouissance. [...] Astre funeste et opiniâtre, l'ordre du jour est venu rétablir les tics et les tracas, les palissades et les tabous » (Monénembo 1991 : 29). Les auteurs africains ont parfois une vision négative de l'aube, à la différence des Latino-Américains qui la campent positivement. L'aube d'Aléjo Carpentier (1993: 220) «ramène toujours la joie intime, atavique d'ancêtres qui, pendant des milliers d'années, vivent quotidiennement dans le petit jour la fin de leurs terreurs nocturnes, le recul des rugissements, l'éloignement des ombres, la confusion des spectres, la mise en déroute du mal ».

L'aube conserve encore l'intégralité de sa charge poétique. Elle avait des « doigts de rose » pour Homère et « une gueule de tenailles » chez René Char (Dubois 1983). La multiplication des situations chaotiques est une exaltation du désastre universel.

Les romanciers épousent la beauté de l'abîme parce qu'ils vivent intérieurement un besoin pressant de retrouver le vide originel en anéantissant le présent. Ils se complaisent dans l'anarchisme parce que les valeurs en vogue ne ménagent pas leur liberté et ne satisfont pas à leurs aspirations. Néanmoins, une autre veine, celle idéaliste que reflète si bien Les gardiens du temple de Cheikh Hamidou Kane (1995) défend encore les traditions avec la même partialité, le même manichéisme des années anti-coloniales. Tous les romanciers du Sud ne sont pas encore guéris de la contamination 
du panégyrique, du besoin de ressourcement vis-à-vis des valeurs ancestrales. En littérature, les idées et les formes du passé, douées d'une rémanence en perpétuel renouvellement, résistent longtemps aux attaques et aux velléités révolutionnaires des générations suivantes.

En nourrissant leurs textes cosmopolites et polyphoniques du tragique et de la dérision des dieux animistes, les romanciers du Sud les font revivre autrement. L'animisme survit dans des événements surnaturels, voire irrationnels, tels que le fantastique urbain. Les pratiques s'y rapportant reculent certes, mais sont transférées dans l'imaginaire collectif, le folklore, la culture populaire. Les écrivains les récupèrent pour les pérenniser sous un mode provocateur. La comparaison de la contemplation des dieux animistes entre plusieurs écrivains du Sud a permis de dégager la communauté d'esprit des romanciers africains, antillais et latino-américains. Les études comparées menées jusqu'ici sur ces littératures émergentes, celles de P. Brunel et Y. Chevrel (1989), Daniel-Henri Pageaux (1994), Romuald Fonkoua (2001) plus précisément, ont proclamé leur très forte similitude.

Département de Lettres modernes, Université Abdou Moumouni, Niamey.

\section{BIBLIOGR APHIE}

Albouy, P.

1968 La création mythologique chez Victor Hugo, Paris, Corti.

Amado, J.

1976 La boutique aux miracles, Paris, Stock.

BÂ, A. H.

1994 Contes initiatiques, Paris, Stock.

BÂ, A. H. \& Elugo, E.

1965 Les religions africaines traditionnelles, Paris, Éditions du Seuil.

BAKHTine, M.

1987 Esthétique et théorie du roman, Paris, Gallimard.

BENAC, H.

1988 Guide des idées littéraires, Paris, Hachette. 
Bessis, $\mathrm{H}$.

1987 «La bacchanale et sa représentation dans les arts plastiques », in A. FAIVRE \& F. TRIstan (dir.), Le mythe et le mythique, Paris, Albin Michel : 121-143.

Billault, A.

1991 La création romanesque dans la littérature grecque à l'époque impériale, Paris, PUF.

BonI, N.

1962 Crépuscule des temps anciens, Paris, Présence africaine.

Bounfour, A.

1994 «Les Djinns : comment communiquer avec son génie», in C. G. Dubois (dir.), L'imaginaire de la communication, Bordeaux, Presse Universitaire de Bordeaux.

Brunel, P. \& Chevrel, Y.

1989 Précis de littérature comparée, Paris, PUF.

Carelli, M. \& Galvãor, W. N.

1995 Le roman brésilien: une littérature anthropophage au $X^{e}$ siècle, Paris, PUF.

Carlier, C. \& Gritton Rotterdam, N.

1994 Des mythes aux mythologies, Paris, Ellipses.

CARPentier, A.

1993 Le partage des eaux, Paris, Gallimard.

Chamoiseau, P.

1992 Texaco, Paris, Gallimard.

Chateaubriand, F. DE

1966 Génie du christianisme, Paris, Flammarion.

CONDE, M.

1992 Les derniers rois mages, Paris, Mercure de France.

2000 Célanire cou-coupé, Paris, Robert Lafont.

Confiant, R.

1997 Chimères d'En-ville. Traduit du créole par J.-P. ARSAYE, Paris, Ramsay.

DAOUDA, B.

1997 La création romanesque chez Tierno Monénembo, écrivain africain francophone, Thèse de Doctorat, Bordeaux, Université Michel de Montaigne.

Delas, D.

1996 «Pelourinho ou le carnaval des identités », Notre Librairie, 126 : 109-110.

Diop, B.

1947 Les contes d'Amadou Kounba, Paris, Fasquelle. 
Diop, B. B.

1987 Les tambours de la mémoire, Paris, Nathan.

Diop, C. A.

1959 L'Unité culturelle de l'Afrique noire, Paris, Présence africaine.

Dubois, C. G.

1983 «Les réseaux symboliques et leur fonction littéraire», Versant (Littérature et mythe), $4: 5-31$.

DuPRIEZ, B.

1984 Les procédés littéraires, Paris, Union générale d'éditions.

DURAND, G.

1992 Les structures anthropologiques de l'imaginaire, Paris, Dunod.

FonKouA, M.

2001 Les champs littéraires africains, Paris, Karthala.

HАMа, B.

1973 Le double d'hier rencontre demain, Paris, Union générale d'éditions.

JOYCE, J.

1992 Ulysse, t. 1, Paris, Gallimard.

Kane, C. H.

1995 Les gardiens du temple, Paris, Stock.

Kourouma, A.

1990 Monnè, outrages et défis, Paris, Éditions du Seuil.

LAFERRIÈRE, D.

1999 Comment faire l'amour avec un nègre sans se fatiguer, Paris, Le Serpent à plumes.

Mamani, A.

1980 Sarraounia, Paris, L'Harmattan.

MANN, T.

1965 Les Buddenbrook, Paris, Fayard.

Monénembo, T.

1986 Les écailles du ciel, Paris, Éditions du Seuil.

1991 Un rêve utile, Paris, Éditions du Seuil.

1993 Un attiéké pour Elgass, Paris, Éditions du Seuil.

1995 Pelourinho, Paris, Éditions du Seuil.

2000 L'aîné des orphelins, Paris, Éditions du Seuil.

Olivier de SARDAN, J.-P.

1995 Anthropologie et développement, Paris, Karthala. 
Oumarou, I.

1977 Gros plan, Dakar, Nouvelles éditions africaines.

Oulloguem, Y.

1968 Le devoir de violence, Paris, Éditions du Seuil.

Pageaux, H.-D.

1994 Littérature générale et comparée, Paris, Armand Colin.

SANSONNETti, P. G.

1987 « Au commencement était le Graal», in A. FAIVRE \& F. Tristan (dir.), Le mythe et le mythique, Paris, Albin Michel : 81-89.

\section{RÉSUMÉ}

En Afrique, aux Antilles et en Amérique du Sud, les romanciers ont souvent évalué la situation préoccupante des dieux animistes. L'évocation récurrente des puissances transcendantales imprime un cachet particulier à leur univers romanesque. L'originalité des œuvres tient au type de style, de description et de suggestion qu'impliquent l'exaltation ou la condamnation des rites primitifs. La prégnance de l'esprit animiste comble la nostalgie du vieux monde que les auteurs voient voué à la disparition. Leur fétichisme sape les valeurs modernes vis-à-vis desquelles ils éprouvent des sentiments ambivalents. Cet article a tenté d'apprivoiser l'esthétique et la thématique qu'ils déploient pour raconter la vie et la mort des dieux africains.

\section{ABSTRACT}

The Contemplation of Animist Gods in the Novels of the Southern Hemisphere. Novelists in Africa, the west indies and south America have sometimes analysed the worring condition of the animist gods. The rucurrent recalling of transcendental powers communicates a specific style to their romantic universe. The originality of these productions stems from the sort of style, description and suggestions implied by the exaltation or condamnation of primitive rites. The fecundity of the animistic mind gratifies the longing of old world which the authors consider as doomed to disappear. Their fetishism undermines the modern values towards which they have ambivalent feelings. It is worth becoming familiar with the aesthetics and themes dealt with which they make use of in their description of the lives and death of african gods.

Mots-clés/keywords : anarchisme, contemplation, dérision, dieux animistes, modernité, romans du Sud, sentiments ambivalents/anarchism, contemplation, derision, animist gods, modernity, novels of southern hemisphere, ambivalent feelings. 